\title{
Focal Segmental Glomerulosclerosis
}

\author{
Dawinder S. Sohal and Sharma S. Prabhakar \\ Department of Medicine, Texas Tech University Health Sciences Center \\ USA
}

\section{Introduction}

Focal segmental glomerulosclerosis (FSGS) as the name implies is a histopathological pattern of lesions, where the "focal" refers to, involving minority of glomeruli and the "segmental" refers to, involving a portion of the glomerular capillary tuft caused by injury to podocytes (Fig 1A). Clinically it manifests proteinuria which can progress to nephrotic syndrome and eventually to end stage renal failure.

\subsection{Historical aspects}

Karl T. Fahr, a German pathologist, described "Progressive lipoid nephrosis" in 1925 which is currently recognized as FSGS. Arnold Rich (1957) was the first to report segmental sclerosis in juxtamedullary glomeruli in autopsy cases of children with nephrosis and uremia. In this report, he hypothesized that the progression to end stage renal disease (ESRD) in a subset of children with idiopathic nephrotic syndrome was because of the development of glomerular sclerosis. Churg et al published histopathological classification of nephrotic syndrome in children for the International Study of Kidney Disease in Children (ISKDC) in 1970, and the disease entity of FSGS was emphasized as a clinicopathological entity separate from minimal change disease (MCD) by its marked resistance to steroids and progression to ESRD. Habib (1973) described clinical and histopathological features of this entity as a separate disease entity using the term 'focal glomerular scleroses'.

Brown et al (1978) reported the malignant form of FSGS, which is characterized by FSGS with rapid decline in renal function. Howie et al. (1984) described the glomerular tip lesion in FSGS, as glomeruli with segmental lesions at the outer $25 \%$ with adhesion or prominence of podocytes at the tubular neck. Patients with the glomerular tip lesion often develop nephrotic syndrome and have excellent response to steroids, favorable outcome, and their clinical course is similar to that of patients with MCD. Schwartz et al. (1985) reported another form of FSGS-related cellular lesion characterized by glomerular extracapillary epithelial hypercellularity and endocapillary hypercellularity with foam cells and infiltrating leukocytes, and this was considered to represent an early stage in the development of FSGS. Soon after a collapsing form of FSGS as a new clinic-pathological entity was described by Weiss et al. (1986), which is characterized by nephrotic syndrome with progressive irreversible ESRD and by glomerular collapse with epithelial hypercellularity. Subsequently, many cases of renal disease associated with HIV infection, (Rao TK et al 1984) termed as HIV-associated nephropathies, were reported with features similar to the collapsing form of FSGS. 
Between 1980-2000, secondary FSGS (Rennke HG et al. 1989 \& D’Agati V. 1994) was established as FSGS with recognized etiologic associations, including genetic mutations in podocyte-associated proteins, virus, drug toxicities, and structural-functional adaptations. Finally in 2004, the Columbia classification was proposed by D' Agati, Fogo, Bruijn, and Jenette, as a working classification for FSGS as given in table 2. Lately some celebrity figures like Sean Elliott and Alonzo Mourning (National Basketball Association) have been diagnosed with FSGS which has further enhanced awareness of this disease in public.

\subsection{Epidemiology}

Focal segmental glomerulosclerosis (FSGS) currently is the leading cause of nephrotic syndrome in adults and children, particularly in the United States, Australia, Brazil, Canada, Kuwait, India and many other countries. (reference from: http://eng.hi138.com/?i295373_The-epidemiology-of-focal-segmental-glomerulosclerosis). Renal biopsy survey for idiopathic nephrotic syndrome in adults in United States between 1995 to 1997, has revealed that FSGS is the most common cause of nephrotic syndrome, responsible for 35 percent of all cases and more than 50 percent of cases among black population, (67 percent of such cases in black adults were younger than 45 years of age). Idiopathic FSGS is now the most common cause of end stage renal disease (ESRD) caused by primary glomerular disease in the United States in both the black and white populations. The proportion of ESRD attributed to FSGS has increased 11-fold, from $0.2 \%$ in 1980 to $2.3 \%$ in 2000 (excluding patients with HIV). As per Kitiyakara C. et al (2004) the peak decade for FSGS ESRD incidence is 40 to 49 years among black patients as compared to, 70 to 79 years among white and Asian patients. Males have 1.5- to 2-fold greater risk than females. Recent incidence of end stage renal disease secondary to FSGS is five cases per million population in Caucasian US population and 30-40 cases per million population for African-American population (Hogg R. et al 2007).

\section{Etio-pathogenesis}

While majority of FSGS cases are still considered idiopathic, the etiologies and mechanisms involved in FSGS development continue to be elucidated. FSGS can be divided into primary or idiopathic and secondary depending upon if the etiology is unknown vs. known respectively. For FSGS to produce nephrotic range or non-nephrotic range proteinuria, alterations of normal glomerular structure and function has to occur. Normal glomerular function requires, that the three major components of glomerular filter, namely endothelial cells, podocytes, and glomerular basement membrane (GBM), be intact and are able to provide a permselective filtration barrier. Specialized tight junctions between podocyte foot processes create a slit diaphragm (SD) which is integral in preventing the loss of protein into Bowman's space (Kimberly et al. 2007 \& Asanma et al 2003) . Even though the clinical presentation of FSGS is often heterogeneous, a cardinal feature of the disease is proteinuria, which implies loss of this permselective barrier (Schnaper HW, 2003 \& Fogo AB, 2003). Electron microscopic picture clearly reveals distortion of normal architecture (or effacement) of the foot processes of podocytes in FSGS

(Fig 1B).

A key factor in the pathogenesis of FSGS is damage and loss of podocytes. Asanuma K. et al. (2003) described that based on recent insights into the molecular pathology of podocyte injury, at least four major causes have been identified that lead to the uniform reaction of 
pododcyte foot processes effacement and proteinuria: (1) interference with the slit diaphragm complex and its lipid rafts (2) direct interference with the actin cytoskeleton (3) interference with the GBM or with podocyte-GBM interaction, and (4) interference with negative surface charge of podocytes. Damage to podocytes triggers apoptosis and the detachment of podocytes from the glomerular basement membrane. The resulting reduction in podocyte number (podocytopenia) leaves the glomerular basement membrane to be exposed, (Fogo AB 2003) which leads to development of maladaptive interactions between the glomerular basement membrane and epithelial cells. This is followed by proliferation of epithelial, endothelial and mesangial cells. The combined reaction of cell proliferation and leakage of proteins into Bowman's space results in deposition of the collagen. Eventually the capillary loop collapses and endothelial cells are lost and the affected part of the glomerular tuft heals by scarring causing a characteristic lesion of FSGS. Thus the lesions initially are limited to a few segments in the glomerulus (segmental) and in a few regions of the kidney (focal) but the disease ultimately progresses to involve the entire kidney leading to end stage renal disease (ESRD).

The precise initial insult that leads to the above cascade of events is still unknown. A 'circulating permeability factor' which leads to glomerular basement membrane injury has been proposed in the pathogenesis of FSGS (Shalhoub RJ, 1974). The following information favors the hypothesis of 'circulating Permeability factor' (1) frequent recurrence of proteinuria after renal transplant [Ingulli E. et al. 1991] (2) the efficacy of extracorporeal techniques such as plasmapheresis in reducing the post renal transplant proteinuria [Artero M. et al 1992 and 1994]. (3) the results of in vitro bioassay which detects permeability changes induced by FSGS serum on isolated glomeruli [Savin VJ et al in 1992 and 1996].

(4)Rea et al (2001) demonstrated that the main clinical feature of FSGS i.e. proteinuria, disappeared within one year after transplantation in two recipients of kidneys from a patient with FSGS. Not taking into account ethical and legal implications, good outcome of the FSGS allograft kidneys into non FSGS recipients is another good evidence for humoral genesis/circulating permeability factor, as a cause of the FSGS. (5) Kemper M. et al (2001) demonstrated transmission of glomerular permeability factor from the mother affected by FSGS to her infant during gestation. After birth, proteinuria in the child decreased and then disappeared, suggesting a strong correlation with some circulating factor transmitted from the mother to the child.

At the molecular level, cytokines and vasoactive factors are believed to play a major role in the progression of FSGS. The overexpression of transforming growth factor $\beta$ (TGF $\beta$ ) or its downstream proteins, the 'Smads' lead to glomerulosclerosis in animal models. Activation of the renin-angiotensin system upregulates TGF $\beta$, which is considered to cause further progression of the disease (Harris RC et al. 2006). Angiogenic factors, like platelet-derived growth factor (PDGF) and vascular endothelial growth factor (VEGF) seem to play a role in disease progression. This is based upon the rat remnant kidney model (RK model) experimental studies of progressive glomerulosclerosis. In this model, VEGF upregulation soon after the renal injury and later loss of VEGF expression correlates well with progression of the glomerulosclerosis (Kang DH et al. 2001).

Mechanical stress is also believed to play a role in the progression of FSGS. (Hostetter TH. 2003 \& Kwoh C. et al 2006) The hyperfiltration due to the defects of the filtration barrier results in increased single nephron glomerular filtration rate (SNGFR), which results in hypertrophy of glomeruli. The hypertrophy exacerbates the mismatch between the glomerular basement membrane and the decreased numbers of podocytes, propagating the 
injury further. Another factor in the progression of FSGS is tubulointerstitial injury. Clinically, tubulointerstitial injury is a predictor of the loss of renal function in FSGS (D'Agati VD 2003 \& Rodriguez-Iturbe B et al. 2005). The nonspecific entry of proteins into the tubular lumen is one potential source of damage to the tubulointerstitium. Indeed, persistence of nephrotic-range proteinuria is a negative prognostic factor for the progression of FSGS to ESRD (Walls J. 2001). Cytokines (such as TGF $\beta$ ), when present in the tubules, will recruit monocytes, macrophage, and T-cells. This stimulates other cytokines, including interleukin-1, tumor necrosis factor alpha, and other chemokines. This inflammatory infiltrate leads to mesangial matrix deposition, promoting the collapse of glomeruli. The cellular infiltrate and cytokines also damage tubular epithelial cells, and some tubular epithelial cells may undergo transformation to mesenchymal cells. These mesenchymal cells, as well as recruited and stimulated fibroblasts, result in collagen matrix deposition and tubulointerstitial fibrosis

(Harris RC et al. 2006).

Regardless of the cause of podocyte injury, when the podocytes start dying, leakage of protein across the GBM leading to proteinuria and hypoalbuminemia ensues. At this time cholesterol levels start rising due to increased synthesis of cholesterol by the liver and loss of lipid regulating proteins in the urine, the underlying mechanism of these effects is not completely known yet. The beneficial effects of blocking the renin-angiotensin system may not be limited to their antiproteinuric or antihypertensive effects. As noted earlier, angiotensin stimulates TGF $\beta$, in turn contributing to fibrosis. In addition, angiotensin affects intracellular calcium concentrations and the podocyte cytoskeleton (Harris RC et al. 2006). Inhibition of angiotensin may slow progression by these local mechanisms (Korbert SM, 2003).

With increasing incidence of FSGS, these pathways of podocyte injury and disease progression provide important targets for future intervention. Trials have already been initiated to antagonize cytokines, such as TGF $\beta$ (as discussed later in this chapter in treatment section).

Genetic mutations seen in congenital forms of nephrotic syndrome and FSGS enabled researchers to identify specific gene mutations involved in podocyte damage (Tryggvason K. et al. 2006). Mutations of the nephrin gene, a podocyte-specific transmembrane component of the slit diaphragm, are found in congenital Finnish-type nephrotic syndrome, and may lead to loss of normal caliber slit diaphragms. (Kestila M. et al. 1998, Tryggvason K. et al. 2006, Kwoh et al. 2006). In mouse models, mutations of nephrin-like transmembrane genes (NEPH-1) which also localize to the slit diaphragm result in proteinuria and early death. Other proteins which are part of the slit diaphragm complex include: podocin, CD2associated protein (CD2AP), FAT, P-cadherin,ZO-1, LAP (leucine rich repeat and PDZ domain) protein. (Asanuma K et al 2003, Tryggvason K. et al. 2006). Mutations in podocin (a transmembrane protein that interacts with nephrin, NEPH-1 and CD2AP) have been identified in familial FSGS. Recently, mutations in CD2AP, an immunoglobulin-like protein that is involved in nephrin integration with podocyte cytoskeleton, have also been linked to genetic forms of FSGS (Shih NY. et al. 1999, Kim JM et al 2003, Tyggvason K. et al 2006). In mouse models, the loss of FAT1 and FAT2 (transmembrane proteins with cadherin-like repeats) results in the absence of slit diaphragms, proteinuria, and early death. Alphaactinin-4, an important structural component of the podocyte cytoskeleton, is mutated in some autosomal dominant forms of FSGS (Kaplan JM et al 2000, Yao J et al. 2004). In addition to the abnormal structural proteins mutations, some other mutations have been 
identified in association with FSGS like TRPC6 (Transient receptor potential cation chanel, subfamily $C$, member 6) which is a cation-selective, ion-channel protein that mediates calcium signals (Winn MP et al. 2005). The role of the other components of the slit diaphragm in the pathophysiology of FSGS is not yet clear.

In summary, these data suggest that mutations in the cytoskeleton and membrane proteins specific to podocytes are responsible for most inherited forms of disease. The frequency of spontaneous mutations in the general population who develop nephrotic syndromes or FSGS still needs to be assessed as it has diagnostic, prognostic and therapeutic implications in case of FSGS. For example, patients who possess genetically defective podocytes should be unresponsive to conventional steroid treatment. Similarly, these patients should not have recurrent FSGS when transplanted with a structurally normal kidney allograft. Furthermore, family members who are potential living donors could be genetically screened for mutations associated with the development of kidney disease and excluded as candidate donors.

\section{Secondary FSGS}

Secondary FSGS can be seen in a variety of conditions such as renal agenesis, obesity, or sickle cell disease etc where hyperfiltration is a characteristic abnormality. Glomerulomegaly is common in situations with hyperfiltration. Obesity-associated FSGS needs a definitive diagnosis with a renal biopsy to exclude the presence of concurrent early diabetic nephropathy. Secondary FSGS may also result from intravenous drug abuse and reflux disease. It has been reported that toxins, including lithium and pamidronate, and sirolimus are associated with the development of FSGS lesions. Among the viral infections, HIV is the most common cause. Rarer viral causes of secondary FSGS include persistent parvovirus B19, simian virus 40 , and cytomegalovirus infection.

\section{Clinical presentation}

Primary FSGS more likely presents with sudden-onset nephrotic syndrome, whereas secondary FSGS presents more insidiously with subnephrotic range proteinuria and renal insufficiency. But the secondary FSGS from pamidronate toxicity though typically presents with full nephrotic syndrome and acute or subacute renal failure, with collapsing FSGS lesions on biopsy. Physical exam reveals elevated blood pressure and edema. Urine may be foamy and may have hematuria. The relative frequencies of these findings at presentation or biopsy based diagnosis in published series (Rydell JJ et al. 1995 \& Chun MJ et al 2004) are as follows. Primary FSGS can present with nephrotic range proteinuria (60 to $75 \%$ ), microscopic hematuria with variable degrees of proteinuria (30 to $50 \%$ ), hypertension (45 to $65 \%$ ), renal insufficiency ( 25 to $50 \%$ ) and with overlapping of these presentations. Children tend to present with more proteinuria whereas hypertension is more common in adults. A case of FSGS should be considered idiopathic only when other etiologies are thoroughly excluded. Uncommonly Muehrcke's lines (white banding on the nails due to hypoalbuminaemia), xanthelasma and xanthomata (cholesterol deposits in skin) are associated with FSGS as well. Following risk factors need to be considered when doing history and physical examination on such patients: male gender, black race, positive family history, heroin abuse, use of known causative medications, chronic viral infection, a solitary kidney, and obesity. 
Primary or idiopathic FSGS: Refer to Table 2

Secondary FSGS:

1. Virus assoiated

a. HIV associated nephropathy (HIVAN)

b. Parvovirus B19

c. SV40

d. CMV

2. Drug toxicity
a. Pamidronate
b. Lithium
c. Interferon -alpha
d. Heroin
e. Sirolimus

3. Secondary FSGS mediated by adaptive structural-functional responses

a. Reduced renal mass

Unilateral renal agenesis

Oligomeganephronia

Renal dysplasia

Reflux nephropathy

Sequela to cortical necrosis

Surgical renal ablation

Chronic allograft nephropathy

Any advanced renal disease with reduction in functioning nephrons

b. Initially normal renal mass

Obesity

Hypertension

Atheroembolic or other acute vaso-occlusive processes

Cyanotic congenital heart disease

Sickle cell anemia

Anabolic steroids

4. Familial FSGS

a. Autosomal recessive :

mutations in genes NPHS1 (coding for nephrin) ,NPHS2 (coding for podocin) and PLCE1 (coding for PLC epsilon1)

LAMB2 (coding for Laminin beta 2 chain)

b. Autosomal dominant

Mutations in genes ACTN1 (coding for alpha actinin4), TRPC6 (coding for TRPC6),

INF2 (coding for INF2)

WT1 (coding for WT1)

Table 1. Etiologic Classification of Focal Segmental Glomerulosclerosis 
Differences in clinical manifestations correlate with differences in pathologic phenotypes. Collapsing variant of FSGS often has more severe proteinuria and renal insufficiency but less hypertension than typical variant. Patients with collapsing FSGS frequently have extrarenal manifestations of the disease, a few weeks before the onset of the nephrosis e.g. episodes of upper respiratory infections, diarrhea that are usually ascribed to the viral or other infectious processes. However, the symptoms of fever, anorexia, aches and pains are present only in $20 \%$ of patients at the time of onset of nephrosis. Glomerular tip lesion variant (Fig 4) often presents with rapid onset of edema similar to minimal change disease. Glomerular tip lesion patients may develop reversible acute renal failure, at the times of initial presentation when the degree of proteinuria, edema, hypoalbuminemia are at their peak. This behaves like minimal change disease and this rarely happens in any other forms of FSGS. Patients with glomerular tip lesion FSGS tend to be older white males in comparison to younger black males predominance in collapsing variant FSGS.

Distinguishing between primary and secondary FSGS is important, since secondary FSGS should not respond to immunosuppressive therapy. Instead, the inciting condition or toxin should be alleviated or stopped in secondary form FSGS if possible. Unfortunately, distinguishing between primary vs. secondary FSGS can be challenging, since focal sclerosis lesions may be present in a diverse assortment of glomerular, vascular, and tubular injuries, just as global sclerosis represents a common endpoint lesion for the end-stage renal disease.

\section{Laboratory findings}

Urine analysis may have wide range of findings starting from fatty casts to dysmorphic red blood cells and red blood cell casts. Proteinuria varies from less than $1 \mathrm{gm}$ to $30 \mathrm{~g} /$ day. Hypoproteinemia is common in patients with FSGS, with total serum protein reduced to varying extents. Hypoalbuminemia may drop as low as below $2 \mathrm{~g} / \mathrm{dL}$, especially in patients with the collapsing and glomerular tip variants of FSGS. Cholesterol levels are increased. Serum complement components are typically in normal range in FSGS. CD4 cell count and HIV test is essential in all patients with FSGS, especially those with the collapsing pattern. DNA/PCR for Parvo B19 and CMV test is an essential part of work up to rule out the rare forms of secondary FSGS. Finally renal biopsy is the final step to make the diagnosis of FSGS.

\section{Histopathology}

The diagnosis of FSGS is not an easy one to make, because the morphologic features of FSGS are nonspecific and can occur in a variety of other conditions or superimposed on other glomerular disease processes. Additionally, because the defining glomerular lesion is focal, it may not be adequately sampled in small needle biopsies. The diagnosis of FSGS is further complicated by the existence of a primary (or idiopathic) form and many secondary forms (Table 1). Before a diagnosis of primary FSGS can be made, secondary forms must be excluded. Idiopathic FSGS must be distinguished from human immunodeficiency virus (HIV) -associated nephropathy, heroin nephropathy and other large group of secondary FSGS caused by structural-functional adaptations mediated by intrarenal vasodilatation, and increased glomerular capillary pressures, (as listed in Table 1). The morphological types are not used to guide treatment but to provide useful prognostic information. Electron microscopy can be used to distinguish primary and secondary FSGS. In primary FSGS, foot process fusion is diffuse and occurs throughout the glomeruli. In secondary FSGS, foot process fusion is mostly limited to the sclerotic areas. 
Five main light microscopic patterns of FSGS have been defined, as given below:

\begin{tabular}{|c|c|c|}
\hline Variant & Positive Criteria & Negative Criteria \\
\hline FSGS NOS & $\begin{array}{l}\text { At least one glomerulus with segmental increase in matrix } \\
\text { obliterating the capillary lumina. } \\
\text { There may be segmental glomerular basement membrane } \\
\text { collapse without podocyte hyperplasia. }\end{array}$ & $\begin{array}{l}\text { Exclude perihilar,cellular,tip and } \\
\text { collapsing variant. }\end{array}$ \\
\hline Perihillar Variant & $\begin{array}{l}\text { Perihillar sclerosis and hyalinosis involving }>50 \% \text { of } \\
\text { segmentally sclerotic glomeruli. }\end{array}$ & $\begin{array}{l}\text { Exclude cellular,tip and collapsing } \\
\text { variant. }\end{array}$ \\
\hline Cellular Variant & $\begin{array}{l}\text { At least one glomerulus with segmental endocapillary } \\
\text { hypercelllularity occluding lumina, with or without foam } \\
\text { cells with karyorrhexis. }\end{array}$ & Exclude tip and collapsing variant. \\
\hline Tip variant & $\begin{array}{l}\text { At least one segmental lesion involving the tip domain } \\
\text { (outer } 25 \% \text { of tuft next to origin of the proximal tubule) } \\
\text { The tubular pole must be identified in the defining lesion. } \\
\text { The lesion must have either an adhesion or confluence of } \\
\text { podocyte with parietal or tubular cells at the tubular } \\
\text { lumen or neck. } \\
\text { The tip lesion may be sclerosing or cellular. }\end{array}$ & $\begin{array}{l}\text { Exclude callasping variant } \\
\text { Exclude any perihilar sclerosis. }\end{array}$ \\
\hline Collapsing variant & $\begin{array}{l}\text { At least one glomerulus with segmental or global collapse } \\
\text { Podocyte hypertrophy/hyperplasia }\end{array}$ & none \\
\hline
\end{tabular}

Classified based upon the 'Working Columbia Classification 2004'.

Table 2. Morphological variants of FSGS

Although appearance of the glomerular tuft differs in these forms, all share the common feature of podocyte alterations at the ultrastructural level. At present, it is unclear if these morphologic variants reflect pathogenetic differences or they are the consequence of different severities of podocyte injury or histopathologic evolution. Future studies are needed to address these questions.

Classic Focal Segmental Glomerulosclerosis (Focal Segmental Glomerulosclerosis Not Otherwise Specified) : also called FSGS NOS, or typical FSGS. FSGS NOS requires exclusion of the other more specific subtypes described in the table 2. Light Micrscopic examination reveals accumulation of extracellular matrix which occlude glomerular capillaries, forming discrete segmental solidifications involving affected portion of the glomerular tuft. Also seen is plasmatic insudation of amorphous glassy material beneath the GBM, endocapillary foam cells, and wrinkling of the GBM. Adhesions to Bowman's capsule are common, and overlying visceral epithelial cells often appear swollen over the sclerosing segment. Non sclerotic glomerular lobules appear normal by light microscopy except for mild podocyte swelling. Immunofluorescence: focal and segmental granular deposition of $\operatorname{IgM}$, and C3 is seen often, but $\mathrm{C} 1$ in the distribution of segmental glomerular sclerosis may also be seen. Nonsclerotic glomeruli may have weak mesangial staining for IgM and C3. By electron microscopic examination, segmental sclerotic lesions exhibit increased matrix, wrinkling and retraction of GBM. Accumulation of inframembranous hyaline material but no immune complex electron-dense deposits are seen. Overlying the segmental sclerosis, there is usually 
effacement of foot processes (Fig 1.B)and podocyte hypertrophy. The adjacent nonsclerotic glomerular capillaries show only foot process effacement.
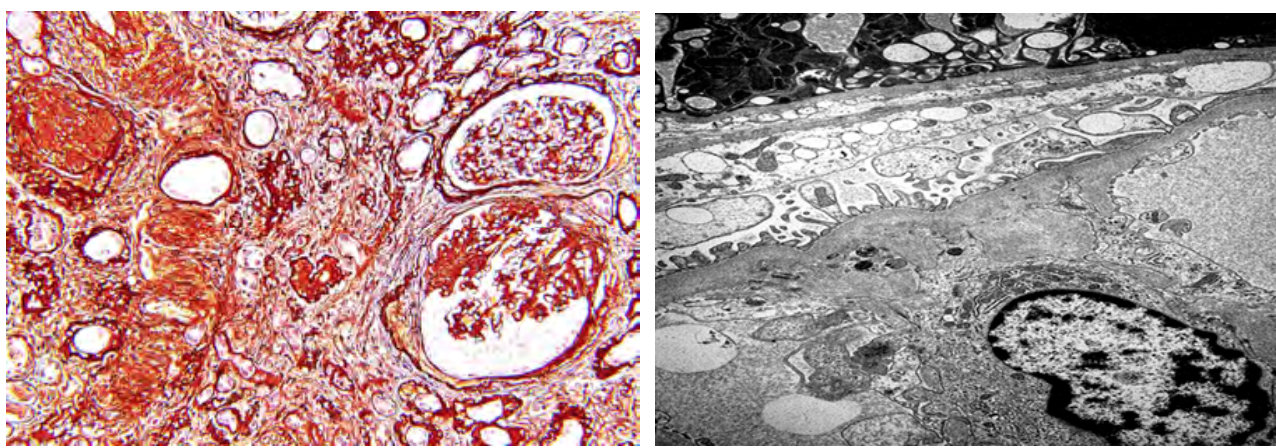

Fig. 1. (A-left) Focal segmental distribution of glomerular lesions. The glomerulus at the top right of the picture is normal. The glomerulus at the bottom shows dense segmental scars with adhesion to Bowman's capsule. (Periodic acid methenamine silver, 20X). (B-Right) Patchy effacement of foot processes is present. No immune complex-type deposits are seen along the GBM. (Electron Microscopy).

Perihilar Variant of Focal Segmental Glomerulosclerosis : This variant is defined as perihilar hyalinosis and sclerosis (Fig 2. A \& B) which involves more than $50 \%$ of glomeruli with segmental lesions. This category requires that the cellular, tip, and collapsing variants be excluded. Podocyte hyperplasia is uncommon.
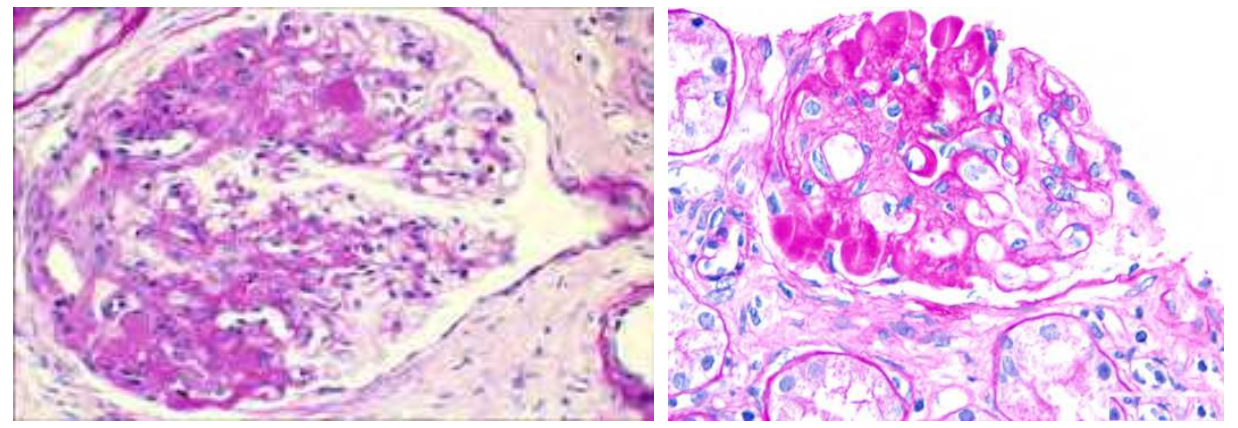

Fig. 2. (A-left): Perihillar variant FSGS (B): Glomerulus with "Hyalinosis": homogeneous, eosinophilic material may be present at the periphery of sclerotic foci, or within the capillary subendothelial space (PAS, 40X). (Fig 2A-obtained from http://www.unckidneycenter.org/kidneyhealthlibrary/fsgs.html\#causes)

Immunofluorescence (IF) reveals segmental deposits of IgM and C3 in areas of sclerosis and hyalinosis.

Electron microscopy (EM) demonstrates variable foot process effacement. The perihilar variant may occur in primary or secondary FSGS. It is more common in secondary forms of FSGS mediated by adaptive structural-functional responses, in which it is typically accompanied by glomerular hypertrophy. In this setting, the greater filtration pressures at 
the proximal end of the glomerular capillary bed may favor the development of lesions at the vascular pole.

Cellular Variant of Focal Segmental Glomerulosclerosis : This variant is characterized by focal and segmental endocapillary hypercellularity that may mimic a form of focal proliferative glomerulonephritis. Glomerular capillaries are segmentally occluded by endocapillary hypercellularity, including foam cells, infiltrating leukocytes, karyorrhectic debris, and hyaline. There is often hyperplasia of the visceral epithelial cells, which may appear swollen and crowded, sometimes forming pseudocrescents. This variant requires that tip lesions and collapsing lesions be excluded.

IF shows focal and segmental glomerular positivity for IgM and C3 and EM reveals severe foot process effacement.

Collapsing Variant of Focal Segmental Glomerulosclerosis: This variant is defined by at least one glomerulus with segmental or global collapse (Fig 3) and overlying hypertrophy and hyperplasia of visceral epithelial cells. There is occlusion of glomerular capillary lumina by implosive wrinkling and collapse of the GBMs. This lesion is more often global than segmental. Overlying podocytes display striking hypertrophy, hyperplasia and express proliferation markers. Podocytes often contain prominent intracytoplasmic protein resorption droplets and may fill Bowman's space, forming pseudocrescents . Although podocyte hyperplasia is found in both the collapsing and cellular variants of FSGS, collapsing glomerulopathy is distinguished by the absence of endocapillary hypercellularity. In collapsing FSGS, there is prominent tubulointerstitial disease, including tubular atrophy, interstitial fibrosis, interstitial edema, and inflammation. A distinctive feature is the presence of dilated tubules forming microcysts that contain loose proteinaceous casts. This pattern can occur both in primary FSGS and also in secondary FSGS due to HIV,parvovirus B12,pamidronate toxicity and interferon therapy. Endothelial tubuloreticular inclusions are identified in over $90 \%$ of patients with HIVinfection collapsing glomerulopathy and interferon therapy, whereas only in $10 \%$ cases with idiopathic collapsing glomerulopathy. Besides these conditions endothelial tubuloreticular inclusions are seen commonly in systemic lupus erythematosus nephritis.

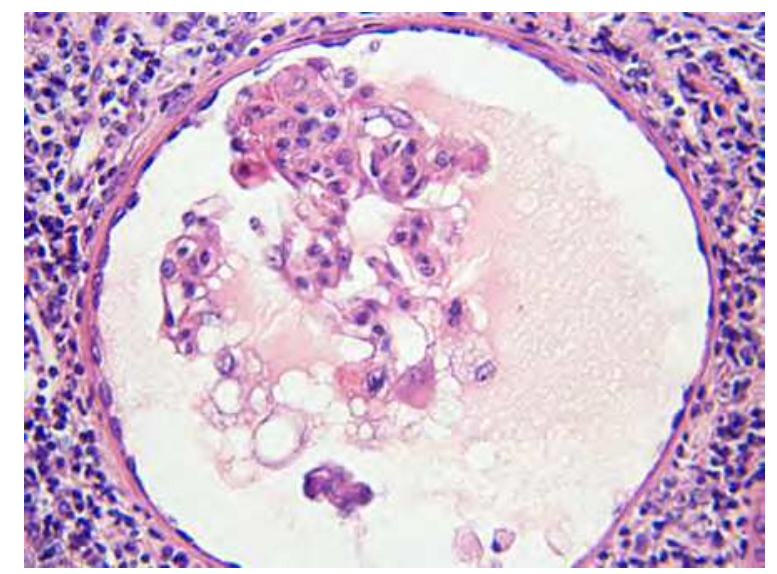

Fig. 3. A glomerulus displays collapsing variant of FSGS, glomerular capillaries show collapse with absent lumen (H\&E, 40X). 
IF microscopy of collapsing lesions often is positive for IgM and C3. EM reveals severe foot process effacement affecting both collapsed and noncollapsed glomeruli

Tip Variant of Focal Segmental Glomerulosclerosis :

This variant is defined by the presence of at least one segmental lesion involving the tip domain (i.e., the outer $25 \%$ of the tuft next to the origin of the proximal tubule). There is either adhesion (Fig 4) between the tuft and Bowman's capsule or confluence of swollen podocytes with parietal or tubular epithelial cells at the tubular lumen or neck. In some cases, the affected segment appears to herniate into the tubular lumen. The segmental lesions may be cellular or sclerosing type. Although initially peripherally located, these lesions may progress more centrally. The presence of perihilar sclerosis or collapsing sclerosis rules out the tip variant.

IF microscopy reveals involved tip area positive for IgM and C3 and EM findings demonstrate foot process effacement.

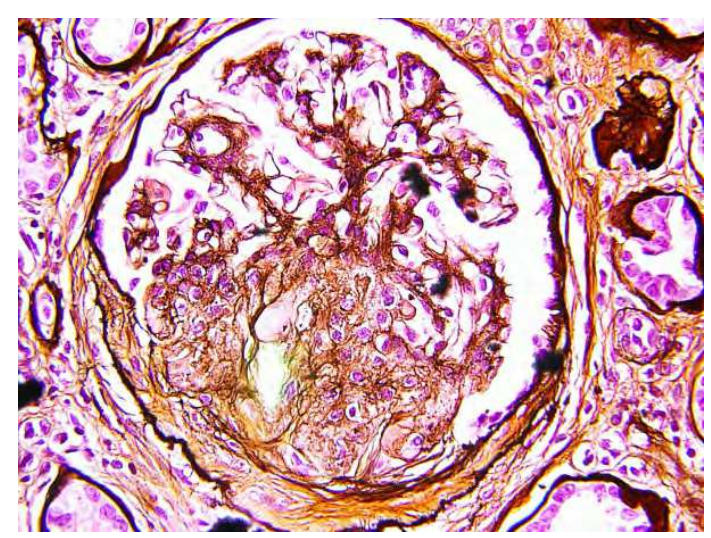

Fig. 4. Sclerotic glomerular segment with a small adhesion; "Glomerular tip lesion“ (Periodic acid methenamine silver, 40X)

\section{Treatment}

Typically the goals of treatment in FSGS include-(1) to reduce, eliminate or at least suppress the proteinuria and (2) to avoid or at least retard the progression to ESRD. Treatment of the FSGS can be arbitrarily divided into (1) Nonspecific; nutritional management (2)Non immunosuppressive therapy: diuretics and RAS interference. (3) Immunosuppressive treatment: which includes the use of steroids, steroid sparing medications like cyclophosphamide, cyclosporine A, tacrolimus and mycophenolic mofetil. (4)-Antifibrotic drugs:Pirfenidone, Rosiglitazone (FONT Phase 1 trial completed and now FONT phase II trial is ongoing) (5)-Monoclonal/polyclonal Antibodies: Adalimumab, Rituximab, Fresolmumab (6)-Plasmapheresis

Nonspecific treatment: Nonspecific treatment goals in FSGS are like any other glomerulopathy associated with nephrotic syndrome, which include maintenance of adequate nutrition, minimization or elimination of proteinuria, and prevention of complications resulting from edema. The mainstay of treatment is reduction in daily salt intake to $2 \mathrm{~g}$ of sodium. A high level of protein intake may further aggravate proteinuria, adversely affecting renal function. Current recommendations call for an intake of 1 to $1.3 \mathrm{~g}$ of 
high biologic value protein per kilogram of body weight and a reduction of fat intake. Lipid lowering is necessary to reduce cardiovascular risk and to possibly delay the progression of renal disease.

\subsection{Non-immunosuppressive drug treatment}

Symptomatic relief of edema helps the patient feel better. In most patients, loop diuretics are needed to promote diuresis. Patients with massive edema with impaired oral absorption may require intravenous administration of loop diuretics. In patients with refractory conditions, addition of other diuretics (eg, metolazone) and potassium-sparing agents (eg, spironolactone, triamterene) facilitates diuresis and prevents hypokalemia. Rarely, some patients (especially children) with intractable edema may need intravenous albumin and diuretics in a hospital setting to initiate diuresis. Protracted use of intravenous albumin should be discouraged; the regimen is expensive and ineffective, because most of the infused albumin is lost in the urine. Continuous IV drip of furosemide is preferred over large boluses of IV push to avoid side effects.

Control of hypertension is one of the most important aspects of overall management in FSGS, like any other glomerular disease. Angiotensin-converting enzyme inhibitors (ACEIs) and angiotensin receptor blockers (ARBs) are nonspecific agents that reduce proteinuria because of their antihypertensive and intrarenal hemodynamic effects of reducing glomerular capillary pressure and resistance. ACEIs and ARBs are effective in reducing protein loss even in normotensive patients. These agents do have an effect in slowing down of the disease progression by downregulating the TGF $\beta$ by interfering with renin angiotensin system, regardless of any antihypertensive effects.These agents do not abolish proteinuria completely or reverse the primary glomerular disease process per se.

As hypertension develops in most patients with FSGS which further causes deterioration of renal function, the control of blood pressure is an important part of the treatment of FSGS. Many patients, may require combination antihypertensive therapy to maintain blood pressure in the normal range. Lipid lowering therapy like statins is warranted to correct hyperlipidemia to reduce the risk of cardiovascular disease in this subset of patient population.

\subsection{Immunosuppressive treatment}

Idiopathic FSGS is a difficult disease to treat because of its highly variable clinical course. The specific treatment approach is still empirical, and no consensus has evolved because of a lack of prospective controlled trials. Current evidence is, mostly derived from retrospective analyses, and favors prolonged steroid therapy (6 months or longer) to induce remission in patients with idiopathic FSGS.

Criteria for remission: (1) complete remission is considered when urinary protein excretion of less than $200-300 \mathrm{mg} /$ day, and (2) partial response is considered when urinary protein excretion of $200-3500 \mathrm{mg} /$ day, or a greater than $50 \%$ reduction in baseline proteinuria.

Since long-term steroid therapy is not without serious toxicity, the patient counselling regarding the goals of the therapy, possible potential side affects and expected outcomes, is essential before starting such treatment. The current consensus is to initiate therapy with prednisone in a dose of $1 \mathrm{mg} / \mathrm{kg}(60-80 \mathrm{mg} / \mathrm{d})$ for 2-6 months or longer, depending on patient's response as assessed by presence or absence of edema, 24-hour urine protein excretions, creatinine clearance, serum creatinine, serum albumin, and lipid levels. Literature reveals that $30-60 \%$ of patients may undergo complete or partial remission with 
this treatment regimen, and relapses are frequent when steroids are discontinued. Blacks and patients with collapsing FSGS are generally refractory to treatment and progress to renal failure. In steroid responsive patients, the goal is to titrate prednisone to the lowest dose needed to stop proteinuria and to prevent relapses. Use of steroids on alternate days can also reduce toxicity. The optimal duration of treatment is uncertain; some authorities recommend use of steroids indefinitely. If no remission after 4 months of corticosteroid treatment, disease is defined as being corticosteroid-resistant (Meyrier A.,2009).

In patients who are refractory to $2-3$ months of prednisone therapy, the recommendation is to reduce the steroid dose and to add cyclophosphamide $(2.5 \mathrm{mg} / \mathrm{kg}$ [150-200 mg/day]), monitor patients for bone marrow suppression, and encourage adequate fluid intake to prevent hemorrhagic cystitis. Prolonged use of cyclophosphamide may lead to gonadal toxicity; therefore, persisting with cyclophosphamide beyond 3 months in patients who do not respond is unwise. Cyclosporine $(3.5 \mathrm{mg} / \mathrm{kg} /$ day) can induce remission and preserve renal function, although relapse occurs in $60 \%$ of patients when cyclosporine alone is used (Ponticelli C. et al. 1993 \& Cattran DC et al. 1999). Continuing treatment with cyclosporine for 1 year after remission followed by a slow tapering of the dose results in a longer remission (Meyrier A 1994). Low-dose cyclosporine in combination with low-dose prednisone $(0.15 \mathrm{mg} / \mathrm{kg} /$ day $)$ in corticosteroid-resistant patients is more effective than cyclosporine alone (Cattaran DC. Et al 1999 \& Meyrier A 2009). Rates of complete (Niaudet P. 1994 \& Braun $\mathrm{N}$ et al 2008) and partial remission achieved with cyclosporine are greater if low-dose prednisone is given at the same time. Continuous use of cyclosporine for $>12$ months is associated with a significant increase in tubulointerstitial fibrosis. Its use should, therefore, be limited to patients with creatinine clearance $>60 \mathrm{ml} / \mathrm{min} / 1.73 \mathrm{~m}^{2}$

Isolated reports have suggested that patients who are refractory to steroids and cyclophosphamide, treatment with other immunosuppressive agents, such as tacrolimus and sirolimus, may be beneficial in inducing remission. However, studies using these agents were uncontrolled investigations that were limited to a few patients.

\subsection{Tacrolimus}

Few studies have reported the use of tacrolimus for Idiopathic FSGS. In the largest study, 25 patients with nephrotic syndrome due to primary FSGS and known resistance to or dependence on cyclosporine (cyclosporine) were given tacrolimus plus prednisolone (prednisone) for 6 months. Seventeen patients had a reduced proteinuria to $<3 \mathrm{~g} /$ day, and 12 had complete or partial remission. Thirteen patients relapsed after discontinuing tacrolimus; reinstitution of therapy for 1 year resulted in complete remission (5 patients) and partial remission (4 patients). [Segarra A et al 2002].

\subsection{Mycophenolate mofetil}

Mycophenolate mofetil (MMF) is a reversible inhibitor of inosine monophosphate dehydrogenase (IMPDH) in purine biosynthesis. MMF is selective for the de novo pathway critical to lymphocytic proliferation and activation. Because of favorable results in other glomerular diseases, mycophenolate mofetil has also been evaluated in FSGS. Although the experience is limited, the suggested dose is 750-1000 mg twice daily in patients who are refractory to corticosteroids and in whom calcineurin inhibitors may not be appropriate. However, adequate randomized studies supporting this approach are lacking (Cattran DC et al. 2004). If mycophenolate is being considered, cyclosporine should not be used concurrently. Mycophenolate can be either used alone or in combination with corticosteroids. 


\subsection{Monoclonal antibody treatment}

Rituximab: Rituximab is an anti CD20 chimeric monoclonal antibody. Case reports have suggested rituximab may be effective in treating patients with minimal change nephropathy and FSGS. (Peters HP et al 2008). Four patients with nephrotic syndrome due to minimal change nephropathy or FSGS were treated with rituximab because of failure of or intolerance to the standard immunosuppressive therapy. Other cases of FSGS reported in the literature (6 pediatric patients) that were successfully treated with rituximab were also included. Complete remission was reported within 1 month for a 7-year-old boy with FSGS during treatment with rituximab and concurrent treatment with mycophenolate, low-dose prednisolone (prednisone), and tacrolimus. Controlled trials are needed to further evaluate the efficacy of rituximab in FSGS.

Fresolimumab: Recently a phase one trial (Trachtman H. et al 2011) has been completed which evaluated the safety and pharmacokinetics of single-dose infusions of fresolimumab, a human monoclonal antibody that inactivates all forms of transforming growth factor-beta (TGF- $\beta$ ), in a phase I open-label, dose-ranging study. Patients with biopsy-confirmed, treatment-resistant, primary FSGS with a minimum estimated glomerular filtration rate (eGFR) of $25 \mathrm{ml} / \mathrm{min}$ per $1.73 \mathrm{~m} 2$, and a urine protein to creatinine ratio over $1.8 \mathrm{mg} / \mathrm{mg}$ were enrolled. All 16 patients completed the study in which each received one of four single-dose levels of fresolimumab (up to $4 \mathrm{mg} / \mathrm{kg}$ ) and was followed for 112 days. Fresolimumab was well tolerated with pustular rash, the only adverse event, developing in two patients. Single-dose fresolimumab was well tolerated in patients with primary resistant FSGS. Additional evaluation in a larger dose-ranging study is necessary.

\subsection{Antifibrotic agents}

Pirfenidone has been shown to have therapeutic potential in fibrotic diseases, although the mechanism of action is not well understood. It has been shown to reduce transforming growth factor- $\beta 1$ production, antagonize TNF- $\alpha$ signaling, and scavenge reactive oxygen species. It also reduces fibrosis and prevents loss of glomerular filtration in animal models of renal disease. An open-label trial evaluated the safety and efficacy of pirfenidone in patients with idiopathic and post adaptive FSGS. Pirfenidone had no effect on BP or proteinuria but it did preserve renal function. Controlled trials are needed to further evaluate the efficacy of pirfenidone in FSGS (Cho ME. et al 2007).

Rosiglitazone: Renal mesangial cells express peroxisome proliferator-activated receptor (PPAR -gamma). PPAR-gamma activation, can exhibit anti-inflammatory effects. Weissgarten et al (2006) demonstrated that PPAR-gamma activation by rosiglitazone resulted in decreased manifestation of inflammatory hallmarks, including inhibition of mesangial cell proliferation, downregulation of apoptosis and blunted responsiveness to angiotensin II in animal models. FONT-I (a phase 1 clinical trial) showed that this agent was safe and well tolerated in 11 patients with biopsy-demonstrated FSGS. The results of further studies are awaited.

Despite all attempts, some patients continue to deteriorate and progress to ESRD. Patients and their families should be counselled in detail regarding the treatment options for ESRD so that they can choose appropriate treatment tailored to their life style among maintenance hemodialysis, continuous ambulatory peritoneal dialysis, or renal transplantation. FSGS may recur in the transplanted kidney, but most centers do not consider this a contraindication for renal transplantation. 
Secondary FSGS treatment management is directed toward the etiology or associated disorder. For example, discontinuing pamidronate in pamidronate induced FSGS, and in HIV-associated FSGS, HAART is associated with remission of proteinuria and preservation of renal function. In heroin-associated FSGS, discontinuation of the drug may result in remission of proteinuria and improvement in renal function.

\section{Prognosis}

Prognosis of idiopathic FSGS is variable. Important prognostic factors are, the amount of proteinuria, the level of plasma creatinine, the morphological subtype, and the response to therapy as listed in table 3. Korbet SM (1999) described that nephrotic patients with FSGS, particularly those with massive proteinuria, have a significantly poorer prognosis than nonnephrotic patients, with $50 \%$ progressing to end-stage renal disease (ESRD) over 3-8 years as compared with a 10-year survival of $>80 \%$, respectively. In addition, the recurrence rate of this lesion is high in transplanted patients with primary FSGS. When clinical and histological features at presentation have been evaluated by multivariate analysis, the significant positive predictors of progression to ESRD have consistently been the serum creatinine $(>1.3 \mathrm{mg} / \mathrm{dl})$, amount of proteinuria and the presence of interstitial fibrosis $(>$ or $=20 \%$ ). The one factor which is a significant negative predictor of progression to ESRD is the achievement of a remission in proteinuria. Unfortunately, spontaneous remissions are rare in FSGS, occurring in $<$ or $=6 \%$ of patients only.

1. Clinical features at the time of biopsy

a. Nephrotic range proteinuria or massive proteinuria

b. Elevated serum creatinine

c. Black race

2. Histopathologic features at the time of biopsy

a. Collapsing variant

b. Tubulointerstitial fibrosis

3. Clinical features during the course of the FSGS

a. Failure to achieve partial or complete remission.

Table 3. Risk factors for progressive loss of renal function in FSGS

Thomas DB et al. (2006) described that the morphological subtype identified on renal biopsy also provided useful prognostic information. The collapsing variant, the main variant seen in HIV-induced FSGS, is associated with a worse prognosis than the other forms. The tip variant has a better prognosis than the other forms.

\section{Summary}

Focal segmental glomerulosclerosis is still largely an idiopathic disease but in the recent past, more genetic mutations and secondary causes have been described. As more and more pathogenetic mechanisms involved in idiopathic FSGS are coming into light and more secondary causes of FSGS are described, the occurrence of true idiopathic FSGS diagnosis is 
decreasing and thus the frequency of the latter is often overstated. Other than the genetic and secondary causes of FSGS, the treatment strategies are still not based upon multiple large randomized controlled trials, and in fact are based upon predominantly anecdotal experiences. Still there are more questions than the answers for the pathogenesis, classification, treatment and prognosis of this an almost a century old disease. This clincopathologic entity still remains a challenge for the nephrologists and transplant physicians.

\section{Acknowledgements}

We acknowledge and thank Irfan Warraich, MD (Dept. of pathology, Texas Tech University Health Science Center Lubbock, Texas) for his generous contribution by providing us with histopathology figures used in this chapter.

\section{References}

Asanuma K, Mundel P (2003) The role of podocytes in glomerular pathobiology. Clin. Exp. Nephrol 7(4):255-259

Bahiense-Oliveira M, Saldanha LB, Mota EL, et al. Primary glomerular diseases in Brazil (1979-1999): is the frequency of focal and segmental glomerulosclerosis increasing? Clin Nephrol 2004; 61:90.

Barisoni L, Kriz W, Mundel P, D’Agati V (1999) The dysregulated podocyte phenotype: a novel concept in the pathogenesis of collapsing idiopathic focal segmental glomerulosclerosis and HIV-associated nephropathy. J Am Soc Nephrol 10 (1):5161

Braden GL, Mulhern JG, O'Shea MH, et al. Changing incidence of glomerular diseases in adults. Am J Kidney Dis 2000; 35:878.

Braun N, Schmutzler F, Lange C, et al. Immunosuppressive treatment for focal segmental glomerulosclerosis in adults. Cochrane Database Syst Rev. 2008;(3):CD003233.

Brown CB, Cameron JS, Turner DR et al. Focal segmental glomerulosclerosis with rapid decline in renal function ("malignant FSGS"). Clin Nephrol 1978: 10: 51

Cattran DC, Appel GB, Herbert LA, et al. A randomized trial of cyclosporine in patients with steroid-resistant focal segmental glomerulosclerosis. Kidney Int. 1999;56:22202226.

Cattran DC, Wang MM, Appel G, et al. Mycophenolate mofetil in the treatment of focal segmental glomerulosclerosis. Clin Nephrol. 2004;62:405-411.

Cho ME, Smith DC, Branton MH, et al. Pirfenidone slows renal function decline in patients with focal segmental glomerulosclerosis. Clin J Am Soc Nephrol. 2007;2:906-913.

Chun MJ, Korbet SM, Schwartz MM, Lewis EJ. Focal segmental glomerulosclerosis in nephrotic adults: presentation, prognosis, and response to therapy of the histologic variants. J Am Soc Nephrol 2004; 15:2169.

Churg J, Habib R, White RH. Pathology of the nephrotic syndrome in children: a report for the International Study of Kidney Disease in Children. Lancet 1970: 760: 1299.

D'Agati V. The many masks of focal segmental glomerulosclerosis. Kidney Int 1994: 46: 1223. 
D'Agati VD, Fogo AB, Bruijn JA, Jennette JC. Pathologic classification of focal segmental glomerulosclerosis: a working proposal. Am J Kidney Dis 2004: 43: 368.

D'Agati VD (2003) Pathologic classification of focal segmental glomerulosclerosis. Semin Nephrol 23(2):117-134

Daskalakis N, Winn MP (2006) Focal and segmental glomerulosclerosis: varying biologic mechanisms underlie a final histopathologic end point. Semin Nephrol 26(2):89-94

Dijkman H, Smeets B, van der Laak J, Steenbergen E, Wetzels J (2005) The parietal epithelial cell is crucially involved in human idiopathic focal segmental glomerulosclerosis. Kidney Int 68 (4):1562-1572

Fahr T. Pathologische anatomie des morbus brightii. In: Henke F, Lubarsch O, eds.

Handbuch der Speziellen Pathologischen Anatomie und Histologie (Vol. 6) ; |Springer, Berlin: 1925; 156

Filler G, Young E, Geier P, Carpenter B, Drukker A, Feber J (2003) Is there really an increase in non-minimal change nephrotic syndrome in children? Am J Kidney Dis 2003: 42(6):1107- 1113

Fogo AB (2003) Animal models of FSGS: lessons for pathogenesis and treatment. Semin Nephrol 23(2):161-171

Ghiggeri GM, Artero M, Carraro M, Perfumo F (2001) Permeability plasma factors in nephrotic syndrome: more than one factor, more than one inhibitor. Nephrol Dial Transplant 16 (5):882-885

Haas M, Meehan SM, Karrison TG, Spargo BH. Changing etiologies of unexplained adult nephrotic syndrome: a comparison of renal biopsy findings from 1976-1979 and 1995-1997. Am J Kidney Dis 1997; 30:621.

Habib R. Focal glomerular sclerosis. Kidney Int 1973: 4: 355.

Harris RC, Neilson EG (2006) Toward a unified theory of renal progression. Annu Rev Med 57:365-380

Hogg R, Middleton J, Vehaskari VM. Focal segmental glomerulosclerosis: epidemiology aspects in children and adults. Pediatr Nephrol. 2007;22:183-186.

Hostetter TH (2003) Hyperfiltration and glomerulosclerosis.Semin Nephrol 23(2):194-199

Howie AJ, Brewer DB. The glomerular tip lesion: a previously undescribed type of segmental glomerular abnormality. J Pathol 1984: 142: 205.

http:/ / eng.hi138.com/?i295373_The-epidemiology-of-focal-segmental-glomerulosclerosis

Johnson RJ (2001) Impaired angiogenesis in the remnant kidney model: I. Potential role of vascular endothelial growth factor and thrombospondin-1. J Am Soc Nephrol 12(7):1434-1447 26.

Kang DH, Joly AH, Oh S-W, Hugo C, Kerjaschki D, Gordon KL, Mazzali M, Jefferson JA, Hughes J, Madsen KM, Schreiner GF,

Kaplan JM, Kim SH, North KN, Rennke H, Correia LA, Tong HQ, Mathis BJ, RodriguezPerez JC, Allen PG, Beggs AH, Pollak MR (2000) Mutations in ACTN4, encoding alpha-actinin-4, cause familial focal segmental glomerulosclerosis. Nat Genet 24 (3):251-256

Karle SM, Uetz B, Ronner V, Glaeser L, Hildebrandt F, Fuchshuber A (2002) Novel mutations in NPHS2 detected in both familial and sporadic steroid-resistant nephrotic syndrome. J Am Soc Nephrol 13(2):388-393 
Kestila M, Lenkkeri U, Mannikko M, Lamerdin J, McCready P, Putaala H, Ruotsalainen V, Morita T, Nissinen M, Herva R,

Kashtan C, Peltonen L, Holmberg C, Olsen A, Tryggvason K (1998) Positionally cloned gene for a novel glomerular protein-nephrin-is mutated in congenital nephrotic syndrome. Mol Cell 1(4):575-582

Kim JM, Wu H, Green G, Winkler CA, Kopp JB, Miner JH, Unanue ER, Shaw AS (2003) $\mathrm{CD} 2$-associated protein haploinsufficiency is linked to glomerular disease susceptibility. Science 300(5623):1298-1300

Kimberly Reidy \& Frederick J. Kaskel. Pathophysiology of focal segmental glomerulosclerosis Pediatr Nephrol (2007) 22:350-354

Kitiyakara C, Eggers P, Kopp JB. Twenty-one-year trend in ESRD due to focal segmental glomerulosclerosis in the United States. Am J Kidney Dis 2004; 44:815.

Korbet SM. Clinical picture and outcome of primary focal segmental glomerulosclerosis. Nephrol Dial Transplant. 1999;14(suppl 3):68S-73S.

Korbet SM (2003) Angiotensin antagonists and steroids in the treatment of focal segmental glomerulosclerosis. Semin Nephrol 23(2):219-228

Kwoh C, Shannon MB, Miner JH, Shaw A (2006) Pathogenesis of nonimmune glomerulopathies. Annu Rev Pathol Mech Dis 1:349-374

Meyrier A, Noel LH, Auriche P, et al. Long-term renal tolerance of cyclosporin A treatment in adult idiopathic nephrotic syndrome. Collaborative Group of the Societe de Nephrologie. Kidney Int. 1994;45:1446-1456.

Meyrier A (2003) E pluribus unum: the riddle of focal segmental glomerulosclerosis. Semin Nephrol 23(2):135-140

Meyrier A. An update on the treatment options for focal segmental glomerulosclerosis. Expert Opin. Pharmacother. 2009;10:615-628.

Niaudet P. Treatment of childhood steroid-resistant idiopathic nephrosis with a combination of cyclosporine and prednisone. J Pediatr. 1994;125:981-986.

Peters HP, van de Kar NC, Wetzels JF. Rituximab in minimal change nephropathy and focal segmental glomerulosclerosis: report of four cases and review of the literature. Neth J Med. 2008;66:408-415.

Ponticelli C, Rizzoni G, Edefonti A, et al. A randomized trial of cyclosporine in steroidresistant idiopathic nephrotic syndrome. Kidney Int. 1993;43:1377-1384.

Rao TK, Fillippone EJ, Nicastri AD et al. Associated focal and segmental glomerulosclerosis in the acquired immunodeficiency syndrome. N Engl J Med 1984: 310: 669.

Rennke HG, Klein PS. Pathogenesis and significance of nonprimary focal and segmental glomerulosclerosis. Am J Kidney Dis 1989: 13: 443.

Rich A. A hitherto undescribed vulnerability of the juxtamedullary glomeruli in lipoid nephrosis. Bull Johns Hopkins Hosp 1957;100: 173-186

Rodriguez-Iturbe B, Johnson RJ, Herrera-Acosta J (2005) Tubulointerstitial damage and progression of renal failure. Kidney Int 68(Supp 99):S82-S86

Rydel JJ, Korbet SM, Borok RZ, Schwartz MM. Focal segmental glomerular sclerosis in adults: presentation, course, and response to treatment. Am J Kidney Dis 1995; 25:534. 
Savin VJ, McCarthy ET, Sharma M (2003) Permeability factors in focal segmental glomerulosclerosis. Semin Nephrol 23(2):147-160

Schnaper HW (2003) Idiopathic focal segmental glomerulosclerosis. Semin Nephrol 23(2):183-193

Schwartz MM, Lewis EJ. Focal segmental glomerular sclerosis: the cellular lesion. Kidney Int 1985: 28: 968.

Schwimmer JA, Markowitz GS, Valeri A, Appel GB (2003) Collapsing glomerulopathy. Semin Nephrol 23(2):209-218

Segarra A, Vila J, Pou L, et al. Combined therapy of tacrolimus and corticosteroids in cyclosporin-resistant or -dependent idiopathic focal glomerulosclerosis: a preliminary uncontrolled study with prospective follow-up. Nephrol Dial Transplant. 2002;17:655-662.

Shih NY, Li J, Karpitskii V, Nguyen A, Dustin ML, Kanagawa O, Miner JH, Shaw AS (1999) Congenital nephrotic syndrome in mice lacking CD2-associated protein. Science 286(5438):312-315

Shimizu A, Higo S, Fujita E, Mii A, Kaneko T. Focal segmental glomerulosclerosis after renal transplantation. Clin Transplant 2011: 25 (Suppl. 23): 6-14.

Thomas DB, Franceschini N, Hogan SL, et al. Clinical and pathologic characteristics of focal segmental glomerulosclerosis pathologic variants. Kidney Int. 2006;69:920-926

Trachtman $\mathrm{H}$. et al; A phase 1, single-dose study of fresolimumab, an anti-TGF-beta antibody, in treatment-resistant primary focal segmental glomerulosclerosis. Kidney International (2011) 79, 1236-1243

Tryggvason K, Patrakka J, Wartiovaara J (2006) Hereditary proteinuria syndromes and mechanisms of proteinuria. N Engl J Med 354(13):1387-1401

Weiss MA, Daquioag E, Margolin EG, Pollak VE. Nephrotic syndrome, progressive irreversible renal failure, and glomerular "collapse": a new clinicopathologic entity? Am J Kidney Dis 1986: 7: 20.

Weissgarten J, Berman S, Efrati S, et al. Apoptosis and proliferation of cultured mesangial cells isolated from kidneys of rosiglitazone-treated pregnant diabetic rats. Nephrol Dial Transplant. 2006;21:1198-1204

Winn MP. Approach to the evaluation of heritable diseases and update on familial focal segmental glomerulosclerosis: Nephrol Dial Transplant 2003 Aug;18 Suppl 6:vi1420.

Winn MP, Conlon PJ, Lynn KL, Farrington MK, Creazzo T, Hawkins AF, Daskalakis N, Kwan SY, Ebersviller S, Burchette

JL, Pericak-Vance MA, Howell DN, Vance JM, Rosenberg PB (2005) A mutation in the TRPC6 cation channel causes familial focal segmental glomerulosclerosis. Science 17(5729):1801- 1804

Walls J (2001) Relationship between proteinuria and progressive renal disease. Am J Kidney Dis 37(1 Supp 2):S13-S16

Weiss MA, Daquioag E, Margolin EG, Pollak VE. Nephrotic syndrome, progressive irreversible renal failure, and glomerular "collapse": a new clinicopathologic entity? Am J Kidney Dis 1986: 7: 20. 
Yao J, Le TC, Kos CH, Henderson JM, Allen PG, Denker BM, Pollak MR (2004) Alphaactinin-4-mediated FSGS: an inherited kidney disease caused by an aggregated and rapidly degraded cytoskeletal protein. PLoS Biol 2(6):787-794 


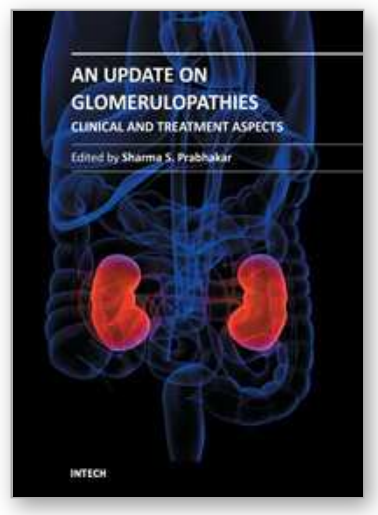

\author{
An Update on Glomerulopathies - Clinical and Treatment Aspects \\ Edited by Prof. Sharma Prabhakar
}

ISBN 978-953-307-673-7

Hard cover, 468 pages

Publisher InTech

Published online 02, November, 2011

Published in print edition November, 2011

An Update on Glomerulopathies - Clinical and Treatment Aspects is a systemic overview of recent advances in clinical aspects and therapeutic options in major syndromes of glomerular pathology. The book contains twenty four chapters divided conveniently into five sections. The first section deals with primary glomerulopathies, and the second section is devoted to glomerulopathies complicating infectious conditions. The third section deals with systemic autoimmune disorders and vasculitides which constitute major causes of glomerular disease and often renal failure. The fourth section includes chapters discussing the glomerular involvement in some major metabolic and systemic conditions. The final section has chapters which relate to some general aspects of glomerular diseases. This book will form an excellent reference tool for practicing and academic nephrology community.

\title{
How to reference
}

In order to correctly reference this scholarly work, feel free to copy and paste the following:

Dawinder S. Sohal and Sharma S Prabhakar (2011). Focal Segmental Glomerulosclerosis, An Update on Glomerulopathies - Clinical and Treatment Aspects, Prof. Sharma Prabhakar (Ed.), ISBN: 978-953-307-673-7, InTech, Available from: http://www.intechopen.com/books/an-update-on-glomerulopathies-clinical-andtreatment-aspects/focal-segmental-glomerulosclerosis

\section{INTECH}

open science | open minds

\author{
InTech Europe \\ University Campus STeP Ri \\ Slavka Krautzeka 83/A \\ 51000 Rijeka, Croatia \\ Phone: +385 (51) 770447 \\ Fax: +385 (51) 686166 \\ www.intechopen.com
}

\author{
InTech China \\ Unit 405, Office Block, Hotel Equatorial Shanghai \\ No.65, Yan An Road (West), Shanghai, 200040, China \\ 中国上海市延安西路65号上海国际贵都大饭店办公楼 405 单元 \\ Phone: +86-21-62489820 \\ Fax: +86-21-62489821
}


(C) 2011 The Author(s). Licensee IntechOpen. This is an open access article distributed under the terms of the Creative Commons Attribution 3.0 License, which permits unrestricted use, distribution, and reproduction in any medium, provided the original work is properly cited. 